Soto Calzado, I. (2018). Diseño de rúbricas para la enseñanza superior del Grabado. Revista Electrónica Interuniversitaria de Formación del Profesorado, 21(1), 173-184.

DOI: http://dx.doi.org/10.6018/reifop.21.1.305311

\title{
Diseño de rúbricas para la enseñanza superior del Grabado
}

\author{
Inocente Soto Calzado \\ Universidad de Málaga
}

\section{Resumen}

Los estudios artísticos han luchado desde sus inicios con la pretendida subjetividad de su enjuiciamiento, un supuesto que ha entorpecido su desarrollo como enseñanza reglada. La disciplina de las Bellas Artes necesita de la utilización de nuevos métodos pedagógicos para su avance educativo. Como parte de ese diseño conceptual que posibilite una mejor enseñanza, la rúbrica es un sistema de evaluación que permite juzgar las competencias propias de toda materia del Espacio Europeo de Enseñanza Superior a partir de la fijación de unos criterios. Con ella se detalla la labor analizada, concretándose al máximo el proyecto común de enseñanza-aprendizaje, y se proporcionan unos indicadores de corrección o incorrección del proceso de gran utilidad para el alumno como guía práctica. Continúa con la tradición de la crítica aplicada a la educación artística. Su presentación visual en forma de tabla con correspondencias y lecturas verticales y horizontales colabora a una rápida comprensión de lo expuesto, permitiendo y demandando el uso de otras herramientas. Su redacción incorpora el lenguaje propio de la materia, buscando su conocimiento y entendimiento. Facilita la práctica de la autoevaluación, y una metaevaluación desarrolla y ajusta el sistema de valoración, buscando una continua retroalimentación.

Palabras clave

Rúbrica; Grabado; Evaluación; Bellas Artes.

\section{Design of rubrics for Printmaking higher education}

\begin{abstract}
Artistic studies have struggled from the outset with the alleged subjectivity of their prosecution, an assumption that has hampered their development as regulated teaching. The discipline of Fine Arts needs the use of new pedagogical methods for its educational progress. As part of this new conceptual design that makes it a better teaching, the rubric is an evaluation system that allows
\end{abstract}

\section{Contacto:}

Inocente Soto Calzado, inocentesoto@uma.es, Facultad de Bellas Artes. Plaza de El Ejido, s/n. 29071 Málaga. 
judging the competences of all European Higher Education Area based on the setting of criteria. The rubric details the work analyzed, defining the common teaching-learning project, and provides indicators of correction or incorrectness of the process that is very useful for the student as a practical guide. Continues the tradition of criticism applied to art education. Its visual presentation in table form with correspondences and vertical and horizontal readings contributes to a quick understanding of the exposed thing, allowing and demanding the use of other tools. Its wording incorporates the language of the matter, seeking its knowledge and understanding. It facilitates the practice of self-evaluation, and a meta-evaluation develops and adjusts the valuation system, looking for continuous feedback.

\section{Key words}

Rubric; Engraving; Assessment; Fine Arts

\section{Introducción a la rúbrica}

La rúbrica nace a principios del siglo XX en forma de escala objetiva de valoración, con el deseo de unificación y homogeneización educativa. La profusión de su estudio en las dos últimas décadas, con su uso en todos los niveles de la enseñanza, es una prueba fehaciente de su necesidad (García-Sanz, 2014). Relacionada con la evaluación, especialmente con la forma de llevarla a cabo, y desarrollada en el mundo anglosajón con el término rubric o scoring rubric como instrumento del profesor y de responsabilización del estudiante (Andrade y Du, 2005), se encuentra en la literatura especializada en castellano también con los nombres de esquema, guía de puntuación, escala o matriz de valoración, procurando explicar el concepto con otros sustantivos y evitar la confusión producida por la traducción literal del término inglés que se ha implantado desde el comienzo de su estudio. Su presentación es de fácil interpretación, mostrando visualmente una gran cantidad de información con la forma de una tabla cuyas filas y columnas llevan básicamente un listado de criterios de evaluación y unos descriptores de niveles de calidad que van desde la excepcionalidad hasta la deficiencia.

Tipos

Dejando a un lado sutilezas e hibridaciones, hablando en términos de extremos una útil clasificación para la redacción de la rúbrica es la que la divide según su finalidad en dos tipos: holística y analítica.

La forma holística está desarrollada para una evaluación global, permitiendo una visión sobre la totalidad de un proceso de enseñanza-aprendizaje sin entrar a analizar sus distintas fases. Se corresponde con la evaluación sumativa en su esfuerzo por chequear el proceso en su momento final y certificar la consecución o no de lo propuesto. Dentro de una corta bibliografía aplicada en materia artística, Connelly y Wolf (2007) crean una rúbrica con este modelo para una clase de final de grado en el área de pintura, juzgando diversas tareas a mitad de curso mediante porcentajes, trabajando sobre amplios conceptos como creatividad (inventiveness), habilidad (craftsmanship) y productividad (productivity); el trabajo previo (sketchbook) se analiza a partir de las tareas realizadas sobre un cuaderno de bocetos, a manera de portafolios, dejando en otro aparte tareas escritas (writing assignments).

La versión analítica también permite evaluar todo o la mayor parte del proceso de enseñanza-aprendizaje, acompañándolo y concentrándose en el análisis parcial buscando posteriormente la síntesis de las distintas partes. La adición de las rúbricas analíticas de las distintas fases y su evaluación permiten una visión holística, que tiene en cuenta, con el aval 
de un número cuantioso de datos, la mayor parte de parámetros posibles del proceso global. Se relaciona con la evaluación formativa en su finalidad de mejora del proceso (Pozo, 2013) y se apoya con rigor en el trabajo conjunto de otros instrumentos, como la lección magistral o el cuaderno de aula, permitiendo una visión completa y compleja del alumno y de su momento de aprendizaje. Es un modelo que permite una fácil realimentación y por lo tanto exige una autoevaluación, una participación, concretando al máximo el plan docente.

\section{Diseño}

La materia evaluada y su especificidad determinan su evaluación y por lo tanto la rúbrica destinada a ello. El enfoque proyectual es algo inherente al hecho artístico, donde el objetivo es que la técnica se convierta en idea y viceversa, con plena funcionalidad (Campuzano, 2008), cubriendo las competencias básicas a adquirir por el alumno dentro del currículo. En esa producción se concentra cotidianamente el ámbito de actuación de las Facultades de Bellas Artes, de lo cual deriva su idiosincrasia frente a diversas disciplinas cercanas, como la Historia del Arte; aunque esta visión haya sido considerada reduccionista, es evidente que el arte se define por su práctica (Agirre, 2005). El diseño se va a realizar sobre la asignatura optativa de $3^{\circ}$ de Grado de Bellas Artes Grabado y Estampación, cuyos contenidos se dividen en 6 bloques temáticos de gran diversidad, donde se analizan conceptos como la obra gráfica, la multiplicidad y la originalidad o la edición limitada, y procedimientos que van desde el monotipo, el grabado en relieve o diversas técnicas de grabado en hueco, directas e indirectas. El aprendizaje de los procedimientos ocupa una gran parte de la carga lectiva, procurando que la enseñanza instrumental sea también una enseñanza conceptual, sin la cual no tendría sentido educativo. Para ir delimitando con mayor acierto cada vez el camino correcto de aprendizaje se van a evaluar individualmente cada una de las tareas relacionadas con los temas, escribiendo para cada uno de ellos una rúbrica diferente.

A pesar de ser una asignatura semestral del penúltimo curso del grado, la experiencia indica que la gran mayoría del alumnado no tiene conocimientos previos sobre la materia, por lo que la rúbrica debe de ser un instrumento, además de evaluación, de comprensión, participación y revisión para alumno y profesor. La idea de reajuste continuo del proceso evaluativo implica una rúbrica analítica, con el mínimo de un diseño por bloque temático, basado en una tarea o proyecto a realizar que conlleva la autoevaluación del alumno mediante la misma rúbrica utilizada por el profesor. Así, de cada rúbrica se obtendrá una puntuación parcial cuya suma valorará la enseñanza-aprendizaje total de la asignatura y permitirá un desarrollo controlado durante la enseñanza y una mejora continua del aprendizaje, ayudado en paralelo con otros documentos como la temporalización y la lista de tareas.

El primer ensayo de rúbrica, como paradigma, se basa en el bloque temático 3, denominado Procesos gráficos de ejecución y estampación en relieve. El grabado en relieve: xilografía, linograbado y nuevos materiales. La transmisión de las ideas debe de ser posible con los medios artísticos, en este caso del grabado en relieve, y con métodos escritos y orales, teniendo en cuenta la complejidad y multiplicidad de facetas en el aprendizaje, no basándose únicamente en la adquisición de conocimiento sino contemplando diversas formas de comunicación, la actitud de superación o la disposición frente al grupo-aula. Acorde con la materia, la metodología a seguir será empírica, con un desarrollo heurístico, fomentando la invención y la búsqueda de estrategias creativas. 


\section{Criterios y competencias}

Siendo la finalidad la evaluación de las competencias, base del Espacio Europeo de Enseñanza Superior, la rúbrica del grabado se impone como un instrumento que debe de ayudar tanto a la consecución de esas competencias como a la comprobación de su adquisición (Tójar y Velasco, 2015). Por lo tanto, hay que partir de las premisas generales y básicas de la asignatura, a disposición del estudiante en la guía docente, para el diseño de dicha rúbrica. El alumno debe de ser capaz de expresar y mostrar sensibilidad, proyectar, investigar desde el pensamiento creativo y aprender de forma crítica y autocrítica.

Específicamente, el alumno va a demostrar mediante la rúbrica conocimientos de instrumentos, métodos, medios y procedimientos, su capacidad de experimentación y creación, sus procesos de reflexión y las dotes de gestión, colaboración y contextualización en su actividad.

Los criterios de evaluación se hacen corresponder con las distintas fases metodológicas de la labor a realizar en cada proyecto temático-técnico, dando la posibilidad de una reflexión sobre cada uno de estos estadios. La primera fase es el tema o planteamiento, seguida de su forma o ejecución, dividiéndose la entrega en otras dos fases: presentación virtual y presentación física. Los componentes de cada fase se detallan, permitiendo su comprensión, por lo que en el diseño se presentan en dos columnas, la primera de las cuales enuncia el criterio globalmente y la segunda lo define en tantos aspectos como se piensen necesarios. Hay criterios de obligado cumplimiento (marcadas con un asterisco), sin los cuales no es posible ninguna valoración, como puede ser el trabajo presencial o la entrega del trabajo.

En general, la mayor parte de los proyectos repetirán sus criterios, salvo por condicionamientos técnicos o conceptuales. Verbigracia, en la primera tarea del curso, dedicada al monotipo, concebida como una introducción a la obra gráfica y a la estampación, la obra se produce a partir de superficies transitorias y no procesadas, no trabajadas permanentemente. La matriz no existe, o se puede considerar efímera (no hay marcas fijadas físicamente sobre la matriz) y se reproduce una imagen de una superficie a otra sin la posibilidad de la igualdad completa de la copia. A veces planteamiento y ejecución se dan simultáneamente, ordenando el azar de las diferentes máculas y cambiando o adaptando la idea primigenia, siendo difícil su evaluación por separado, ya que la forma fácilmente se puede convertir en tema.

Dentro de cada fase / criterio se van a evaluar los contenidos o rubros que se suelen tener en cuenta en planteamientos genéricos sobre arte (Gómez y Huilcapi, 2015) o en rúbricas holísticas. Así, la originalidad, la investigación, la experimentación, la pertinencia o idoneidad, la coherencia, las aplicaciones o aportaciones desde otras áreas o la autonomía se recogen en el planteamiento y la ejecución, y en los dos se valora la comunicación oral transcrita por el profesor en el cuaderno de aula como medio de seguimiento del trabajo presencial. La presentación virtual recoge la comunicación escrita y el manejo tecnológico y tanto esta como la presentación física permiten valorar el compromiso personal.

\section{Descriptores y niveles}

En la literatura sobre rúbricas habitualmente se sugiere la inclusión de un número de descriptores de calidad entre 3 y 5 (Menéndez, 2013). En el diseño se han simplificado, quedando solo los extremos de los niveles de valoración, a pesar de lo aconsejado. Esta reducción a excelencia o deficiencia en la escala de calificación se hace con la idea de no automatizar ni encasillar en exceso el procedimiento, permitiendo la adecuación a todo tipo de obras y de alumnado, dotándolo de la flexibilidad que requiere su empleo en tareas 
diversas, además de ejemplificar los niveles de desempeño correcto e incorrecto sin confusiones, ayudando a su rápida comprensión. Se trata de mantener criterios para el juicio sin convertirlos en estándares fijos e inamovibles, pues la preocupación es la de guiar, no la de medir. Para matizaciones e introducir el criterio matemático de calificación, que es la forma que finalmente adoptará y el alumno encontrará en su evaluación, se añade a la rúbrica la puntuación máxima de los criterios sobre una escala de 10.

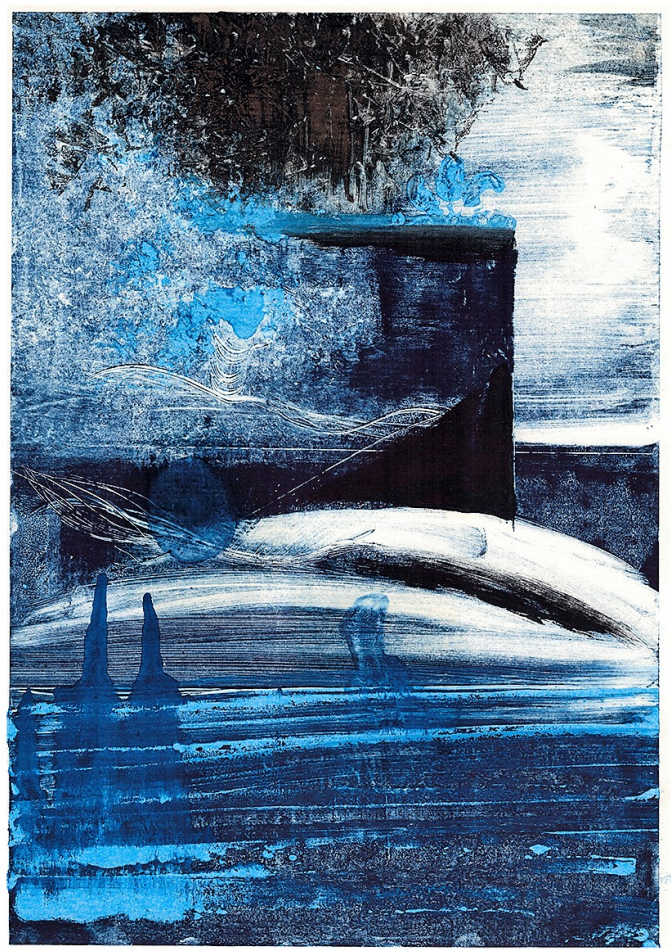

Figura 1. Monotipo, ejercicio curso 2016-2017. Carmen Lozano Aguilar

Así, para una lectura más fácil y una correcta interpretación la tabla tendrá las columnas de Puntuación (de cada fase), Criterios por fases (detallados con su puntuación parcial) y descriptores de calidad (excelente y deficiente) que concretan aún más los criterios. La evaluación no debe de condicionar la labor creativa, por lo que es fundamental la recogida de datos del profesor durante la clase en su cuaderno de aula, que permitirá al docente un acercamiento al desarrollo que cada discente hace del material teórico y el entendimiento sobre sus elecciones artísticas, evitando la obligatoriedad de ejecuciones técnicas o temáticas forzadas en el currículo.

\section{Proyecto de aplicación}

La rúbrica debe hacer más objetivo el proceso de enseñanza-aprendizaje y más efectivo, controlando su desarrollo y ajustando las distintas variables para que la labor de discente y docente sea plena y responsable. Permite una fácil corrección de sus criterios y descriptores, ampliados o reducidos para una nueva utilización tras los datos obtenidos de las distintas evaluaciones. No hay que olvidar la aplicabilidad real del proyecto y su viabilidad en el tiempo. 
Tras una clase magistral sobre los conceptos involucrados en el bloque temático, que implica siempre alguna demostración práctica sobre la técnica, se presenta la rúbrica correspondiente, iniciando su conocimiento y discusión, para que el alumno pueda desde el primer momento utilizarla como elemento de aprendizaje. Tanto la rúbrica como el material didáctico básico se incluyen en la página de la asignatura accesible por Internet, donde el grupo completo podrá utilizar fácilmente toda la documentación (Revuelta y Pérez, 2009), encontrándose con la rúbrica en formato pdf.

Tabla 1.

Rúbrica para el grabado en relieve

\begin{tabular}{|c|c|c|c|c|c|}
\hline COMPETENCIAS & P. & Fases & Criterios & Excelente & Deficiente \\
\hline 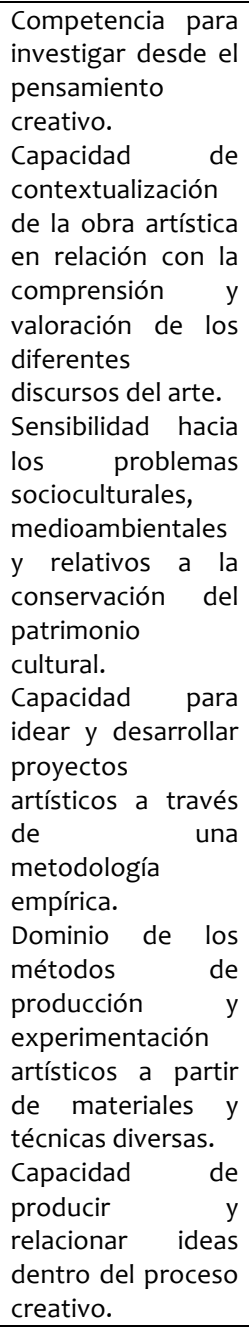 & $2^{\prime} 5$ & $\begin{array}{l}\text { Tema/ } \\
\text { Plantea } \\
\text { miento }\end{array}$ & $\begin{array}{l}\text { o’5 Personalización } \\
\text { Autonomía } \\
\text { Originalidad } \\
1 \text { Composición } \\
\text { Investigación } \\
\text { Formas } \\
\text { *1 Trabajo presencial } \\
\text { y no presencial } \\
\text { Aportaciones }\end{array}$ & $\begin{array}{l}\text { Atención a la clase inicial. } \\
\text { Aprovechamiento. } \\
\text { Ideas previas consolidadas } \\
\text { (bocetos). } \\
\text { El tema se aleja de } \\
\text { estereotipos y de } \\
\text { imágenes conocidas. } \\
\text { Composición. Buena } \\
\text { distribución de la huella en } \\
\text { el papel. Proporción. } \\
\text { Asistencia. Trabajo } \\
\text { progresivo. Horas de } \\
\text { dedicación correctas. } \\
\text { Es capaz de explicar } \\
\text { oralmente su proyecto; } \\
\text { concreta las ideas básicas } \\
\text { con precisión. }\end{array}$ & $\begin{array}{l}\text { Desconocimiento de la } \\
\text { teoría básica. } \\
\text { Sin trabajo previo. } \\
\text { Se utilizan imágenes ajenas, } \\
\text { sin elaboración. } \\
\text { Los distintos elementos no } \\
\text { se interrelacionan } \\
\text { correctamente. } \\
\text { Composición desequilibrada } \\
\text { (huella, papel), mala } \\
\text { colocación en el formato. } \\
\text { Falta de evolución. Falta de } \\
\text { horas de dedicación. } \\
\text { Tiene dificultades para } \\
\text { transmitir su proyecto } \\
\text { oralmente; recurre a lugares } \\
\text { comunes, sin concretar. }\end{array}$ \\
\hline 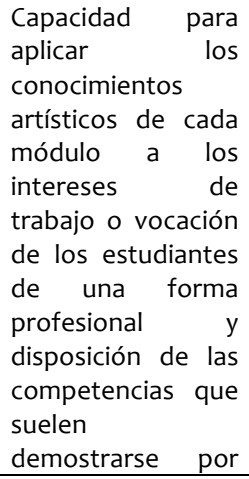 & 3,5 & $\begin{array}{l}\text { Forma/ } \\
\text { Ejecuci } \\
\text { ón }\end{array}$ & $\begin{array}{l}\text { 0'75Procedimientos. } \\
\text { Aportaciones } \\
\text { Variedad } \\
\text { Riesgo } \\
\text { Idoneidad } \\
\text { o'75Coherencia } \\
\text { *2Trabajo presencial } \\
\text { y no presencial }\end{array}$ & $\begin{array}{l}\text { Habilidad. Diversidad } \\
\text { instrumental } \\
\text { Valores aportados } \\
\text { (texturales, gestuales...) } \\
\text { integración en la obra. } \\
\text { Expresividad. } \\
\text { Atención a los } \\
\text { comentarios de clase e } \\
\text { incorporación de las } \\
\text { sugerencias al trabajo. } \\
\text { Desarrollo. } \\
\text { Rectificaciones, utilización }\end{array}$ & $\begin{array}{l}\text { Falta de recursos, labor } \\
\text { inexpresiva, monótona. } \\
\text { Carece de valores plásticos. } \\
\text { Hay una descompensación } \\
\text { en el tratamiento del tono y } \\
\text { contraste. } \\
\text { Falta de elaboración. No } \\
\text { existen estados anteriores. } \\
\text { No tiene en cuenta las } \\
\text { sugerencias realizadas. } \\
\text { Falta de horas de dedicaciór } \\
\text { en el resultado final. (8 }\end{array}$ \\
\hline
\end{tabular}




\begin{tabular}{|c|c|c|c|c|c|}
\hline $\begin{array}{lr}\text { medio de } & \text { la } \\
\text { elaboración } & \text { y } \\
\text { defensa } & \text { de } \\
\text { argumentos y } & \text { la } \\
\text { resolución } & \text { de } \\
\text { problemas dentro } \\
\text { del ámbito de las } \\
\text { Bellas Artes. }\end{array}$ & & & & $\begin{array}{l}\text { creativa de la prueba de } \\
\text { estado. } \\
\text { Asistencia. Horas de } \\
\text { dedicación correctas. }\end{array}$ & $\begin{array}{l}\text { presenciales + } 12 \text { no } \\
\text { presenciales) }\end{array}$ \\
\hline $\begin{array}{l}\text { Conocimiento de } \\
\text { los instrumentos y } \\
\text { métodos de } \\
\text { experimentación } \\
\text { en el arte. } \\
\text { Competencia para } \\
\text { la aplicación de } \\
\text { medios } \\
\text { tecnológicos } \\
\text { digitales en las } \\
\text { prácticas artísticas. } \\
\text { Capacidad para } \\
\text { interrelacionar } \\
\text { distintos medios } \\
\text { en los procesos de } \\
\text { creación artística. } \\
\text { Competencia para } \\
\text { la experimentación } \\
\text { e interrelación de } \\
\text { los distintos } \\
\text { procedimientos } \\
\text { artísticos. } \\
\text { Capacidad arda el } \\
\text { heurística para } \\
\text { desarrollo de } \\
\text { estrategias de } \\
\text { innovación arística. }\end{array}$ & & & & & \\
\hline 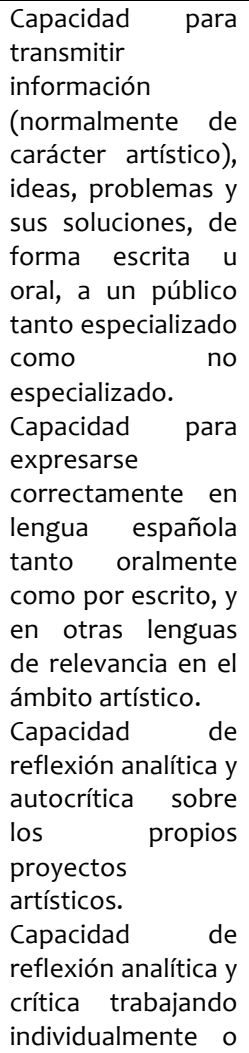 & $*_{2}$ & $\begin{array}{l}\text { Present } \\
\text { ación } \\
\text { virtual }\end{array}$ & 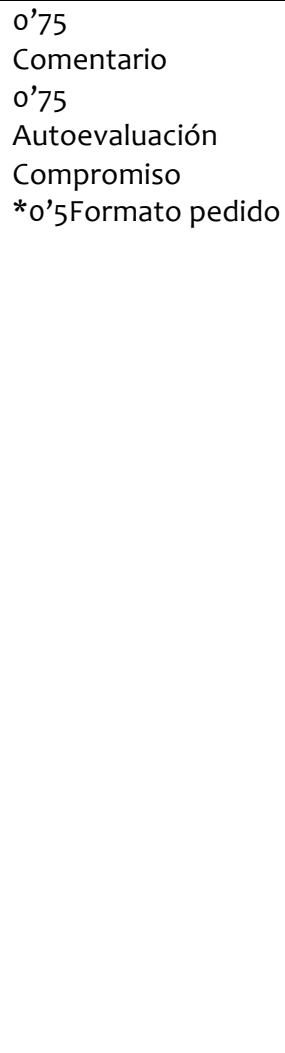 & $\begin{array}{l}\text { Visión personal de las } \\
\text { sesiones de trabajo. } \\
\text { Expresión correcta. } \\
\text { Autoevaluación basada en } \\
\text { la rúbrica. } \\
\text { Imagen clara de la obra, } \\
\text { sin elementos ajenos. } \\
\text { Entrega en plazo y forma } \\
\text { (escritura en foro con } \\
\text { imagen jpg inserta). } \\
\text { Se observa participación. }\end{array}$ & $\begin{array}{l}\text { Problemas de expresión } \\
\text { escrita. No hay comentario, } \\
\text { es demasiado escueto o } \\
\text { impersonal. } \\
\text { No hay autoevaluación o no } \\
\text { se adecua a la obra. } \\
\text { No se respeta el formato } \\
\text { pedido. La imagen no } \\
\text { permite apreciar la obra. } \\
\text { No se aprecia dedicación, no } \\
\text { respeta plazos. }\end{array}$ \\
\hline
\end{tabular}




\begin{tabular}{|c|c|c|c|c|c|}
\hline $\begin{array}{l}\text { en equipo. } \\
\text { Capacidad para } \\
\text { contextualizar el } \\
\text { trabajo personal en } \\
\text { relación a las } \\
\text { últimas tendencias } \\
\text { de la práctica del } \\
\text { arte actual. }\end{array}$ & & & & & \\
\hline $\begin{array}{l}\text { Capacidad para } \\
\text { aprender de forma } \\
\text { crítica y autocrítica. } \\
\text { Competencia para } \\
\text { gestionar, } \\
\text { presentar de forma } \\
\text { adecuada } \\
\text { difundir } \\
\text { producción } \\
\text { artística. } \\
\text { Competencia para } \\
\text { comunicar } \\
\text { presentar ideas y } \\
\text { proyectos } \\
\text { artísticos de forma } \\
\text { adecuada. }\end{array}$ & $*_{2}$ & $\begin{array}{l}\text { Present } \\
\text { ación } \\
\text { física }\end{array}$ & $\begin{array}{l}\text { o'75 } \\
\text { Entintado } \\
\text { o'75 } \\
\text { Estampación } \\
\text { *o'5. Copia }\end{array}$ & $\begin{array}{l}\text { Capa de tinta homogénea. } \\
\text { Biseles limpios } \\
\text { Uso de la plantilla para la } \\
\text { estampación. } \\
\text { Sin huellas en el papel. } \\
\text { Gramaje y textura } \\
\text { correctos. } \\
\text { Firma a lápiz, ángulo } \\
\text { derecho. } \\
\text { Registro perfecto de la } \\
\text { matriz. Nitidez correcta. } \\
\text { Entrega en plazo y forma. } \\
\text { Prensado correcto de la } \\
\text { copia. } \\
\text { Se observa cuidado en la } \\
\text { presentación. }\end{array}$ & $\begin{array}{l}\text { Marcas de rodillo, excesos o } \\
\text { defectos en la cantidad de } \\
\text { tinta. Irregularidad de } \\
\text { biseles o inexistencia. } \\
\text { Mancha descuadrada, sin } \\
\text { márgenes suficientes. } \\
\text { Papel inadecuado } \\
\text { Firma con otros materiales, } \\
\text { descolocada. } \\
\text { Secado no controlado del } \\
\text { papel. } \\
\text { Problemas de presión en el } \\
\text { estampado, falta de nitidez. } \\
\text { Papel ondulado, sin } \\
\text { superficie lisa. } \\
\text { Presentación caótica. }\end{array}$ \\
\hline
\end{tabular}

Junto a esa rúbrica, se dispone de la información de la lista de tareas:

PRÁCTICA No 2

- Realizar un grabado en relieve en formato A5 o similar (tamaño orientativo).

- Estampar en un solo color.

- Proyecto: una estampa cuyo significado se inscriba en la línea de trabajo desarrollada en otras asignaturas por su autor.

- Se elabora la idea durante la semana y se ejecuta y estampa en el taller.

- Se entrega en el Foro de Campus Virtual en la siguiente clase.

- El plazo de entrega presencial finaliza, al igual que la virtual, con la siguiente clase (Cajón de entregas).

MATERIALES A APORTAR POR EL ALUMNO:

LINÓLEO, PVC (SAIPOLÁN), POLIESTIRENO EXTRUIDO

CUCHILLAS, GUBIAS, BURILES

PLANTILLA PARA LA ESTAMPACIÓN (HUELLA, PAPEL).

ACEITE VEGETAL

PAPEL DE GRABADO

TRAPOS, PERIÓDICOS...

Con la temporalización, presente desde el primer día de clase, se entregan al alumno todas las claves temporales para el desarrollo de la tarea y para su organización personal dentro de la dinámica de la asignatura:

$3^{a}$ clase. 9/3/2018. Entrega monotipo Foro Campus Virtual. Entrega monotipo Cajón Entregas Aula. Teoría: El grabado en relieve: El linóleo. Práctica: planteamiento.

$4^{a}$ clase. 16/3/2018. El linóleo. Práctica: ejecución.

$5^{a}$ clase. 23/3/2018. Entrega linóleo Foro Campus Virtual. Entrega linóleo Cajón Entregas Aula. El grabado en hueco. 


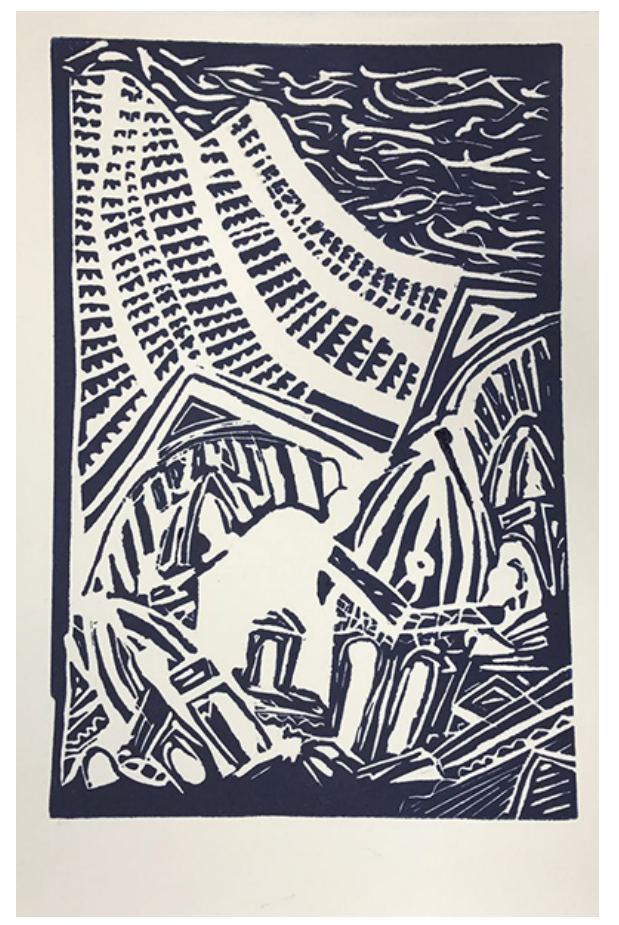

Figura 2. Linóleo, ejercicio curso 2016-2017. Ma Carmen Solís Rodríguez.

Durante las dos sesiones del tema, de unas 4 horas de duración cada una, el profesor anota en el cuaderno de aula el trabajo que lleva a cabo cada pupilo, las conclusiones tras una entrevista oral y su evolución y coherencia con lo expresado. Es importante registrar el nivel inicial del proyecto, anotar los primeros juicios sobre el planteamiento de la obra y recoger las respuestas del alumno durante la ejecución, como la progresión, la atención a las críticas y la reacción a las sugerencias o comentarios, detallados en los descriptores como prueba de la supremacía educativa del proceso sobre el resultado. Tras el término de las sesiones, el alumno cuenta con una semana de plazo para realizar la presentación virtual de la obra, con la imagen, comentario personal y autoevaluación en el foro dedicado a ello en la plataforma educativa; también realizará la presentación física de la estampa, que depositará en una gran cajonera dispuesta para las entregas, donde el docente podrá examinar al mismo tiempo las obras de todo el grupo. En el transcurso de la semana el profesor analiza las entregas virtual y física, estudiando las autoevaluaciones basadas en la rúbrica y comparándolas con su propia evaluación basada en la rúbrica, observando sus anotaciones de clase y deduciendo el trabajo no presencial realizado a partir del conocido, y proporciona telemáticamente, mediante el programa de calificaciones de la misma plataforma, su evaluación individual de la tarea para que el alumno disponga de ella en la siguiente sesión y pueda producirse la realimentación, convirtiéndose en una evaluación formativa real.

\section{Metaevaluación}

Junto a la autoevaluación del alumno y la evaluación del profesor es importante completar el proceso con la evaluación de la propia evaluación, lo que se ha venido en llamar metaevaluación (Santos, 2003). Es una herramienta fundamental de ajuste y perfeccionamiento constante en el diseño de la rúbrica. La forma de realizarla será conocer la opinión más veraz de los protagonistas reales, el alumnado, para poder compararla con las conclusiones del profesor. Para su mayor efectividad será simple y anónima, pensada como encuesta mínima y breve, de formato anónimo y pocas cuestiones, que permita replantear la labor realizada tras el análisis de las opiniones vertidas en ella y su coincidencia 
o desacuerdo con el juicio docente. En este caso la idea será holística, para que permita conocer las virtudes o defectos del sistema de enseñanza-aprendizaje completo.

Es una versión corregida y adaptada de una experiencia similar en el área de Pintura (Soto, 2017), que había arrojado conclusiones positivas. La lectura de los resultados había mostrado claramente una experiencia bien valorada por el alumnado, perteneciente a un grupo heterogéneo formado en sus dos terceras partes por jóvenes que cursaron el bachillerato artístico como vía de acceso a la carrera y en menor medida por personas adultas con una importante vida laboral u otra carrera tras ellas. Era porcentualmente muy bajo aquellos que no veían nada positivo; alto era también el porcentaje de los que subrayaban "solo algunos ítems" como acertados (aunque en ningún caso llegara a la mitad del alumnado), siendo claro el mensaje de la necesidad de una reelaboración de las rúbricas y una afinación especialmente en los apartados de criterios y puntuación, cuestión a tener en cuenta en una aplicación mejorada. Las preguntas 1 y 2 del cuestionario que sirve de base al nuevo desarrollo versaban sobre la capacidad de la rúbrica de explicar el trabajo y su evaluación. Las preguntas 3, 4 y 5 querían conocer la precisión de criterios, descriptores y puntuación. La pregunta 6 cuestionaba la facilidad de la rúbrica y las dos últimas la utilidad de rúbrica y autoevaluación.

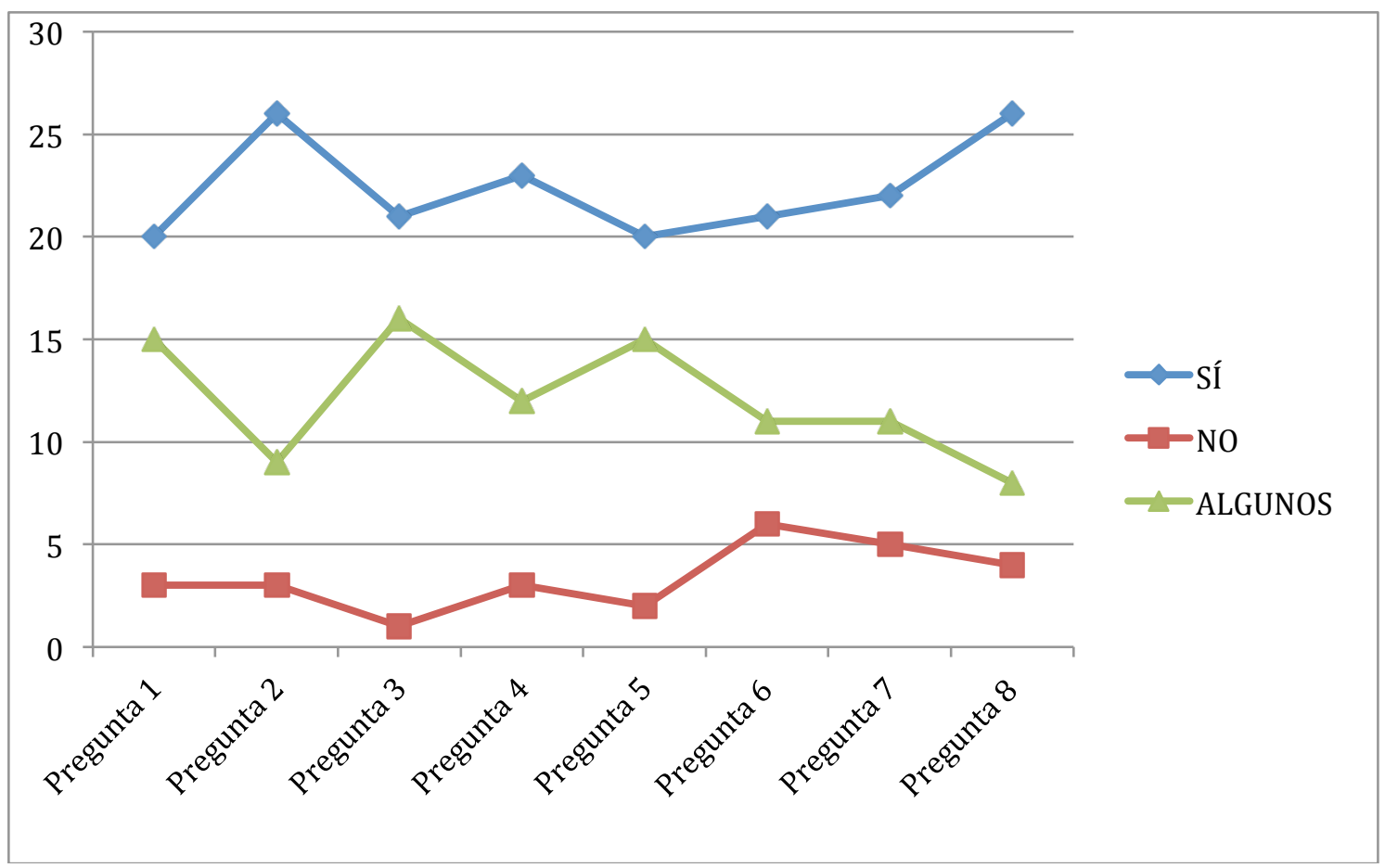

Figura 3. Aceptación del uso de la rúbrica y la autoevaluación en Pintura (tomado de Soto, 2017)

La investigación más genérica de Gómez y Huilcapi (2015) también había descrito satisfactoriamente la percepción del alumno sobre la autoevaluación y sobre otros aspectos sensibles del diseño de una rúbrica, como la claridad evaluadora y su publicidad, aunque no fuera el sistema más utilizado por el profesorado analizado en las encuestas.

Se ha procurado cuidar la redacción de las cuestiones, apurando su definición a partir de las experiencias anteriores, agrupándolas de una forma más racional o si se prefiere operativa, añadiendo dos últimas cuestiones donde se intenta investigar sobre la viabilidad de una extensión de la experiencia a otras materias, dada la relativa novedad de la propuesta en 
este tipo de estudios superiores. Se entregará al final del curso, coincidiendo con la última prueba escrita. Centrados en la rúbrica, las interrogaciones a contestar se dirigen a la claridad para el trabajo y la evaluación, su corrección en cuanto a criterios, descriptores o puntuación y su facilidad y utilidad incluso para otras materias de grado, para descubrir si a criterio de los principales usuarios esto se produce, no se produce o solo a veces. Se pretende con el cuestionario encontrar los puntos de mejora dentro del diseño.

Con el ánimo de no crear dudas en la lectura e interpretación, se redactan las siguientes oraciones:

1. Las rúbricas ayudan a conocer lo que se espera de cada trabajo

2. Las rúbricas ayudan a comprender la evaluación que hace el profesor de los trabajos

3. La rúbrica mejora la enseñanza

4. Las rúbricas son precisas en sus criterios

5. Las rúbricas son claras en sus descriptores de excelencia o deficiencia

6. Las rúbricas son claras en su puntuación

7. La rúbrica está diseñada correctamente

8. La autoevaluación a partir de las rúbricas es fácil

9. La autoevaluación se ha demostrado útil para un mejor aprendizaje

10. Las rúbricas pueden ayudar con otras materias del grado

11. La autoevaluación puede aplicarse positivamente a otras materias del grado

En cada frase se pueden seleccionar una de las siguientes variables:

1. Sí, totalmente

2. No, en absoluto

3. Sólo algunos ítems

A ello se añade un apartado de redacción libre bajo el título "Observaciones personales para mejorar las rúbricas (o la propia encuesta)”, y como guía se adjunta la pregunta "¿Qué debe permanecer, cambiar o añadirse?".

\section{Conclusiones}

La educación es una experiencia, de la misma forma que lo es el arte, y por ello la educación artística debe de cumplir todos esos preceptos marcados por Dewey (2008) en su conocido Arte como experiencia. En él el filósofo resalta el papel de la crítica artística como juicio de valor basado en la percepción, por encima de teorías e ideas adquiridas.

Autores como Eisner (1998) han utilizado las ideas de Dewey para dar cuerpo a una crítica de la educación, pero igualmente sirve su pensamiento para poner en valor una crítica en la educación, dentro de la enseñanza-aprendizaje. La rúbrica y la autoevaluación deben de ayudar a centrar al alumno en el proyecto artístico y sus tareas, permitiéndole sacar mayor provecho de sus esfuerzos, normalizando esa conveniente crítica de análisis y de síntesis en la educación superior, eliminando prejuicios, aprovechando los valores resaltados de promoción de los procesos artísticos y de su vivencia en otras personas, donde el profesor tiene el papel de perceptor privilegiado, expandiendo experiencias en todos los campos de las artes y por lo tanto en el del grabado, pues la función de la crítica es la reeducación de la percepción de las obras de artes, convirtiéndose en un magnífico auxiliar en el difícil proceso de aprender a ver (Dewey, 2008). 


\section{Referencias}

Agirre I. (2005). Teorías y prácticas en educación artística: ideas para una revisión pragmatista de la experiencia estética. Barcelona: Octaedro.

Andrade, H. y Du, Y. (2005). Student perspectives on rubric-referenced assessment, Practical Assessment, Research \& Evaluation, 10(3), 1-11.

Campuzano, E. (2008). La educación artística en el ámbito universitario. En C. Escaño, R. Gutiérrez y L. Martínez (coords.). Nuevas propuestas de acción en Educación Artística (pp. 215-222). Málaga: UMA.

Connelly, M. y Wolf, K. (2007). The Art of Rubrics: Painting by Numbers?, Teaching Artist Journal, 5(4), 279-288.

Dewey, J. (2008). El arte como experiencia. Barcelona: Paidós.

Eisner, E. W. (1998). El ojo ilustrado: indagación cualitativa y mejora de la práctica educativa. Barcelona: Paidós.

García-Sanz, M.P. (2014). La evaluación de competencias en Educación Superior mediante rúbricas: un caso práctico. Revista Electrónica Interuniversitaria de Formación del Profesorado, 17 (1), 87-106.

Gómez, S. y Huilcapi, C. (2015). Propuesta de rúbrica de evaluación para fortalecer los procesos creativos en el aula. Index, revista de arte contemporáneo, 0, 74-87.

Menéndez, J. L. (2013). Rúbricas para la evaluación de proyectos de Aprendizaje-Servicio en los estudios universitarios de las artes. Observar, 7, 5-24.

Pozo, J. A. del (2013). Competencias profesionales: herramientas de evaluación: el portafolios, la rúbrica y las pruebas situacionales. Madrid: Narcea.

Revuelta, F. y Pérez, L. (2009). Interactividad en los entornos de formación on-line. Barcelona: UOC.

Santos, M. A. (2003). Una flecha en la diana. La evaluación como aprendizaje. Madrid: Narcea.

Soto, I. (2017). Una experiencia con la rúbrica en entornos virtuales para la enseñanza superior de la Pintura. En J. Ruiz-Palmero, E. Sánchez-Rivas y J. Sánchez-Rodríguez (edits.). Innovación docente y uso de las TIC en educación. Málaga: UMA.

Tójar, J. C. y Velasco, L. (2015). La rúbrica como recurso para la innovación educativa en la evaluación de competencias. En J. J. Leiva, E. López, A. H. Martín, A. Matas y N. M. Moreno (dirs.). I Seminario Internacional de Innovación Docente e Investigación Educativa (pp. 33-51). Sevilla: AFOE. 